\title{
Decelerator elements for ramp transfer points in fruit packing lines
}

\author{
F.J. García-Ramos ${ }^{\text {a,* }}$, J. Ortiz-Cañavate ${ }^{\text {b,1 }}$, M. Ruiz-Altisent ${ }^{\text {b,1 }}$ \\ ${ }^{a}$ Department of Agriculture and Agricultural Economy, University of Zaragoza, 22071 Huesca, Spain \\ ${ }^{\mathrm{b}}$ Department of Rural Engineering, Polytechnic University of Madrid, 28040 Madrid, Spain \\ Received 7 June 2002; accepted 25 November 2002
}

\begin{abstract}
Two different decelerator elements used to reduce impacts on fruits on ramp transfer points in fruit packing lines were designed and tested.

The performance of these elements, a powered decelerator and a multiple curtain, was compared to commercial decelerators (blankets). A ramp of length $60 \mathrm{~cm}$ was placed at an angle of $30^{\circ}$ in an experimental fruit packing line between a roller transporter and a conveyor. The decelerators were placed on top of the ramp.

Different tests were carried out to study the performance of the decelerators using instrumented spheres (IS 100) of various sizes. Results showed that decelerators can reduce the impact intensity down to safe thresholds. The powered decelerator was the most effective because it reduced the speed of fruits and did not cause retention of the fruit, when correctly regulated.

(C) 2003 Elsevier Science Ltd. All rights reserved.
\end{abstract}

\section{Introduction}

The quality of fruits is one major factor of consumer acceptance. Fruits are exposed to several handling procedures (harvesting, transport, packing) and any damage will reduce the quality and, consequently, the commercial value of the fruit.

Fruit packing lines are one area where mechanical damage occurs, specifically at transfer points where fruit is transferred from one element to the next (Brown et al., 1987).

Instrumented spheres (Zapp, Ehlert, Brown, Armstrong, \& Sober, 1989) are used to study impacts produced on fruit packing lines (Bollen \& De la Rue, 1990; Miller \& Wagner, 1991). Impact data must be related to bruise susceptibility of each fruit type by establishing impact damage thresholds of the products (Chen \& Sun, 1981; Schulte, Timm, \& Brown, 1990). Several studies (Barreiro, 1994) have established $50 g$ (gravity units) as a damage threshold for some fruits like peaches. This threshold is lower for apples.

\footnotetext{
${ }^{*}$ Corresponding author. Address: EPS Huesca, Ctra, Cuarte, s/n 22071 Huesca, Spain. Fax: +34-974239302.

E-mail addresses: fjavier@posta.unizar.es (F.J. García-Ramos), jortiz@iru.etsia.upm.es (J. Ortiz-Cañavate), mruiz@iru.etsia.upm.es (M. Ruiz-Altisent).

${ }^{1}$ Fax: +34-913365845.
}

Impact characteristics depend on different parameters: velocity, transfer height, padding materials and transfer point design. The objective of using a ramp in a transfer point is to reduce the velocity at the moment of the impact against the receptor element. If, for a specific height, the velocity of a sphere in free fall is compared to the velocity of the same sphere in the case of introducing a ramp the result is as follows:

For the case of a free fall $y_{0}$, the potential energy of the sphere before the falling is

$E=m g y_{0}$

The kinetic energy at the moment of impacting will be

$E=\frac{1}{2} m v^{2}$

Then, the velocity at the moment of impacting is

$v=\sqrt{2 g y_{0}}$

In the case of a ramp transfer point (Fig. 1), the potential energy is the same as in Eq. (1). During the movement across the ramp, the sphere has a translation velocity and, at the same time, is turning over its mass centre with an angular velocity $w$. The total energy at whatever position on the ramp is

$E=\frac{1}{2} m v^{2}+m g y+\frac{1}{2} I w^{2}$

The moment of inertia, $I$, is shown in Eq. (5), where $K$ is the radius of gyration of the sphere about its axis 


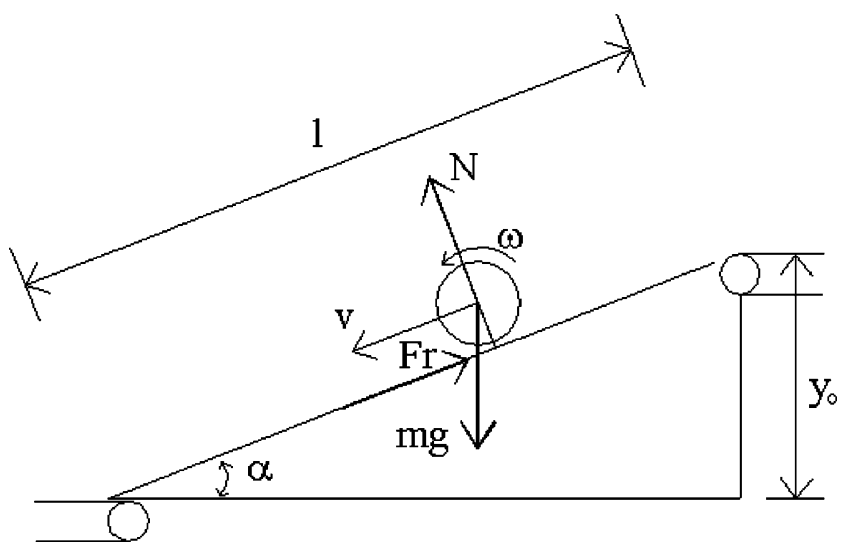

Fig. 1. Dynamics of a ball on a ramp. $N$, Normal force; $m g$, weight of the ball; $f_{\mathrm{r}}$, friction force; $v$, translation velocity; $w$, angular velocity; $\alpha$, ramp angle $=30^{\circ} ; l$, total length of the ramp $=60 \mathrm{~cm} ; y_{0}$, height between the elements implied in the transfer point $=35 \mathrm{~cm}$.

$I=m K^{2}$

Then, the energy at the moment of impacting (base of the ramp, $y=0$ ) is

$E=\frac{1}{2} m v^{2}+\frac{1}{2} m K^{2} \frac{v^{2}}{R^{2}}$

where $v=w R$, and $R$ the radius of the sphere.

Comparing Eq. (6) to Eq. (1), the velocity at the moment of impacting (after the ramp) is

$v=\sqrt{\frac{2 g y_{0}}{1+\left(K^{2} / R^{2}\right)}}$

Comparing Eq. (3) to Eq. (7), we can conclude that the velocity at the moment of impact is lower in the case of using a ramp than in the case of free falling.

More reduction is obtained if friction between fruit and ramp is considered (Fig. 1). In this case the total energy at the end of the ramp is

$E=\frac{1}{2} m v^{2}+\frac{1}{2} m K^{2} \frac{v^{2}}{R^{2}}+E_{\mathrm{f}}$

$E_{\mathrm{f}}=f_{\mathrm{r}} N l=f_{\mathrm{r}} m g \cos \alpha l$

where $E_{\mathrm{f}}$ is the energy lost in rolling friction, $f_{\mathrm{r}}$ is the coefficient of rolling friction; $N$ is the normal force; and $l$ is the length travelled on the ramp.

Comparing Eq. (8) to Eq. (1), the velocity at the end of the ramp, considering friction, is

$v=\sqrt{\frac{2 g\left(y_{0}-f_{\mathrm{r}} l \cos \alpha\right)}{1+\left(K^{2} / R^{2}\right)}}$

Analysing Eq. (10) and Eq. (7), the velocity at the end of the ramp, considering friction, is lower. The velocity at the end of the ramp increases when the angle $\alpha$ is larger ( $\cos \alpha$ is lower). This fact points out the importance of the slope and length of the ramp.
The ramps in fruit packing lines should have a low slope and subsequently a large length to decrease the velocity at the end of the ramp. This fact is really difficult to develop due to the space limitations in the packing lines. Because of that, in spite of the velocity reduction obtained by improving the angle of the ramp, the impact at the end of a ramp can be really significant.

Decelerator elements are necessary to further reduce the velocity of the fruits. The importance of using decelerator elements in fruit packing lines has been described by several authors including Guyer, Schulte, Timm, and Brown (1991) and Ortiz-Cañavate, GarcíaRamos, and Ruiz-Altisent (2000).

Various decelerator elements are being used on transfer points of fruit packing lines, such as powered brushes, curtains, and blankets. Powered brushes and curtains are used successfully in single transfer points with short ramps. In the case of ramp transfer points, blankets are used with a limited success. The effectiveness of the blankets is based on the braking effect on the fruit, which varies according to the dimension and mass of the fruit.

The objective of this work was to develop new improved decelerator elements for ramp transfer points, and to compare their performance to that of traditional elements such as blankets. Several designs were developed, with the aim of reducing fruit velocity in the ramp, and were tested in an experimental fruit packing line (Ortiz-Cañavate, García-Ramos, \& Ruiz-Altisent, 1999) using instrumented spheres.

\section{Materials and methods}

\subsection{Instrumented spheres}

Three different instrumented spheres IS 100 (IS 100G, of $300 \mathrm{~g}$ mass and $8.8 \mathrm{~cm}$ diameter; IS $100 \mathrm{M}$, of $161 \mathrm{~g}$ mass and $7 \mathrm{~cm}$ diameter; and IS $100 \mathrm{P}$, of $115 \mathrm{~g}$ mass and $6.2 \mathrm{~cm}$ diameter) were used to evaluate characteristics of the impacts produced in a ramp transfer point on an experimental fruit packing line (Ortiz-Cañavate et al., 1999). Each impact data is reported relative to the acceleration due to gravity units $(g)$, where $1 g$ is equivalent to $9.8 \mathrm{~m} / \mathrm{s}^{2}$.

Characteristics of IS 100 were: manufactured by Techmark, Inc., sample rate of $3906 \mathrm{~Hz}, g$ sensitivity of 6-300g and accuracy of 3\%. The software used was Pcird version 3.03. The acceleration threshold to be considered zero impact was $8 g$.

\subsection{Ramp transfer point}

Tests were carried out on an experimental fruit packing line located in the Rural Engineering Department at the Polytechnic University of Madrid. A ramp 
transfer point connecting a rollers transporter with a double band conveyor was analysed (Fig. 1). The ramp, designed and constructed for this test, had a total length of $60 \mathrm{~cm}$ and an angle of $30^{\circ}$, connecting two elements with a fall $y_{0}$ of $30 \mathrm{~cm}$ (Fig. 1). The velocity of the rollers transporter and the conveyor during the tests was fixed at $20 \mathrm{~m} / \mathrm{min}$, similar to that of commercial packing lines.

\subsection{Commercial blankets}

The effectiveness of commercial blankets, in reducing impact velocity, was also analysed using the experimental ramp. Blankets of two different lengths, $32 \mathrm{~cm}$ (SB) and $52 \mathrm{~cm}$ (LB), and of two different commercial rubber materials (1 and 2) supplied by the company Maxfrut S.L. (manufacturer of fruit machinery in Levante, Spain) were analysed. Materials 1 consisted of flexible PVC of $2 \mathrm{~mm}$ thickness, and material 2 consisted of EPDM rubber of $2.2 \mathrm{~mm}$ thickness. Characteristics of the blankets tested were as follows:

- LB1, blanket of material 1 and $52 \mathrm{~cm}$ length (Fig. 2);

- SB1, blanket of material 1 and $32 \mathrm{~cm}$ length (Fig. 2);

- SB2, blanket of material 2 and $32 \mathrm{~cm}$ length (Fig. 2);

- $\mathrm{SB} 1+\mathrm{SB} 2$, both blankets were placed over the ramp at the same time (Fig. 3).

An experiment based on a factorial design was carried out, using three IS 100 individually (IS $100 \mathrm{G}$, IS $100 \mathrm{M}$, and IS 100P), four combination of blankets (LB1, SB1, SB2, SB1 \& SB2), and three heights between the fixed part of the blankets and the ramp $(h=10,11$, and $12 \mathrm{~cm}$ ), and without decelerator. For each combination of factors, 20 measurements were taken with each electronic fruit. A total of 960 measurements were taken with the three IS 100 . Once the best regulation was se-

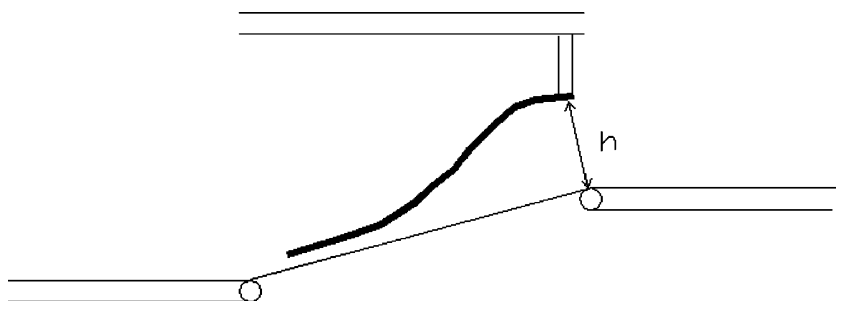

Fig. 2. Single blanket for a ramp transfer point.

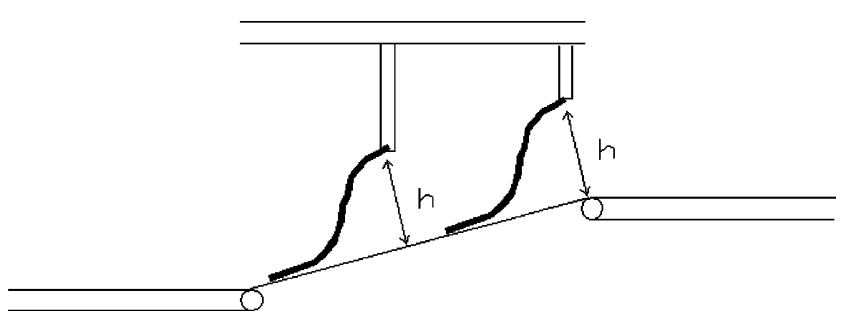

Fig. 3. Double blanket for a ramp transfer point. lected, the decelerator performance was tested with flow of fruit (apples, cv Golden).

\subsection{Multiple curtain}

A decelerator based on a multiple curtain (Fig. 4) was designed and built. In this case the effect is a consistent and cumulative reduction of the speed of the fruit when impacting the receptor element. The decelerator consists of a structure of two metallic guides where several curtains can be placed. Each curtain consists of a group of polythene bristles of $0.20 \mathrm{~cm}$ diameter and $14 \mathrm{~cm}$ height disposed in a width of $25 \mathrm{~cm}$. The decelerator allows different regulations: number of curtains, separation between curtains, curtains characteristics (in this case polythene curtains were used), and height of the tips of the curtains over the ramp. The decelerator was placed on the ramp of the experimental line and was tested according to an experiment based on a factorial design: using the three instrumented spheres individually (IS $100 \mathrm{G}$, IS $100 \mathrm{M}$, and IS 100P), variations in the number of curtains (3 and 6), curtains positioned at three different height settings between the tips of the curtains and the ramp $(-2.25,-1.25,0 \mathrm{~cm})$, and without any decelerator. Negative values point out to the fact that the bottom of the curtain is bent on the ramp. Analysing the number of curtains, the separation between each pair of curtains was $26 \mathrm{~cm}$ for the case of 3 , and $13 \mathrm{~cm}$ for the case of 6 . For each combination of factors, 20 measurements were taken with each electronic fruit. A total of 480 measurements were taken with the three IS 100. Once the best regulation was selected, the decelerator performance was tested with a flow of fruit (apples, cv Golden).

\subsection{Powered decelerator}

A powered decelerator (Fig. 5) was designed and built with the aim of studying its effect on decreasing the impact suffered by the fruit on the ramp transfer point. The decelerator consists of a powered belt with several polythene curtains. Each curtain consists of a group of polythene bristles of $0.20 \mathrm{~cm}$ diameter and $14 \mathrm{~cm}$ height disposed in a width of $25 \mathrm{~cm}$. The fruit settles between each pair of plastic curtains (without passing across) and

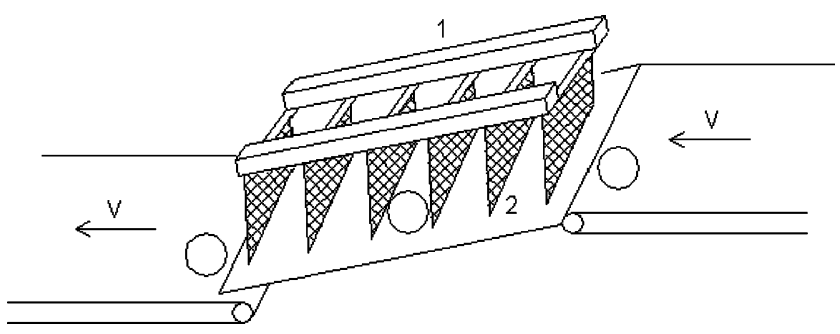

Fig. 4. Multiple curtain for ramp transfer points. (1) guides; (2) elastic curtains. 


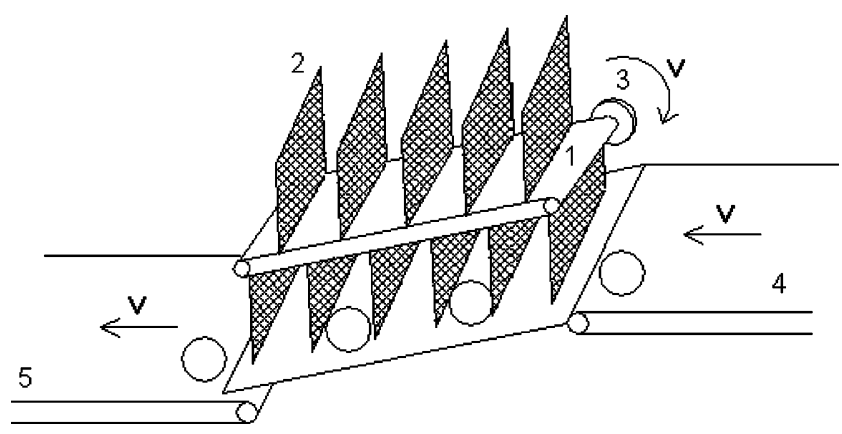

Fig. 5. Powered decelerator for ramp transfer points. (1) belt; (2) elastic curtains; (3) power system.

travels on the ramp till the receiving belt (Fig. 5). The distance between each pair of curtain was $10 \mathrm{~cm}$ with a total of 14 curtains in the decelerator. Curtains must be elastic to decrease the first impact (top of the ramp). Decelerator velocities and belt and receptor velocities must be similar. This way, the speed of the fruit is the same as the speed of the receptor belt, thus eliminating impact velocity. The decelerator element has different regulations: height to the ramp, velocity, and characteristics (firmness) of the elastic curtains.

The decelerator was tested according to an experiment based on a factorial design, using the three IS 100 individually and several regulation heights between the tip of the elastic curtains and the ramp $(0,2.5,4 \mathrm{~cm})$, and without decelerator. For each combination of factors, 20 measurements were taken with each electronic fruit. A total of 240 measurements were taken with the three IS 100 . Once the best regulation was selected, the decelerator performance was tested with flow of fruit (apples, cv Golden).

\section{Results and discussion}

\subsection{Commercial blankets}

Blankets tested showed different performances in the reduction of the impact intensity registered by the instrumented spheres (Fig. 6). SB2 blanket located at 10 $\mathrm{cm}$ height and double blanket SB1 $+\mathrm{SB} 2$ located at 12 $\mathrm{cm}$ height, worked satisfactorily, reducing the impact intensities to less than $40 \mathrm{~g}$. For these combinations, retentions of product were produced when the line worked with flow of fruit.

Using analysis of variance (ANOVA) (Table 1) to know the effect of height, type of blanket and size of IS 100 , all variables had a significant effect. The type of blanket was the most influential variable. The use of SB2, by itself or combined with a second blanket, was the most effective. When using only one blanket SB1 (Fig. 6, SB1), size of the fruit was significant: the deceleration was less for smaller fruits.

\subsection{Multiple curtain}

The efficacy of the multiple curtain in the reduction of the impact intensity is better for the larger number of curtains with smaller height (Fig. 7).

For a height of $-2.25 \mathrm{~cm}$, the instrumented sphere IS $100 \mathrm{G}$ was not able to pass through the decelerator

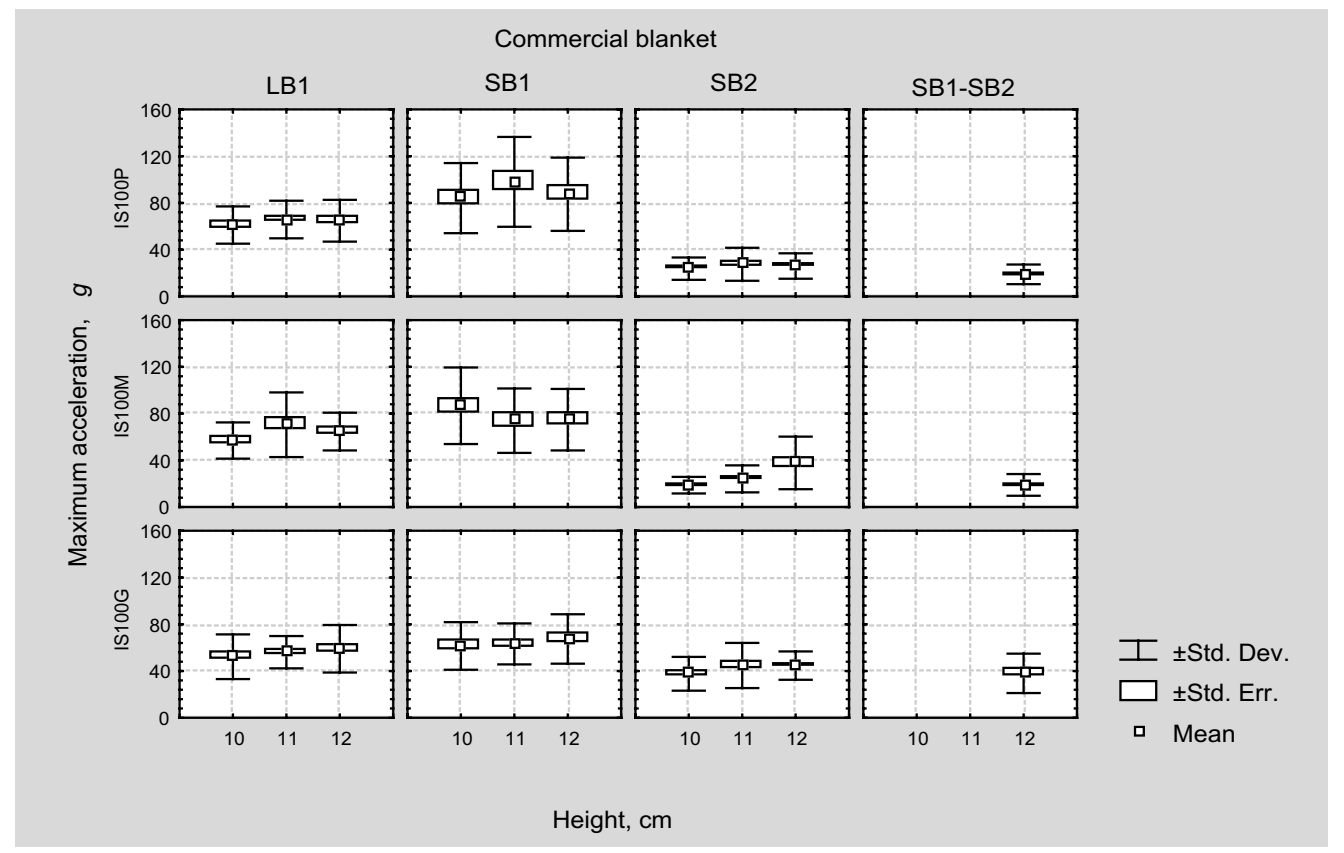

Fig. 6. Maximum acceleration registered by the instrumented spheres (IS 100P, M, and G) in function of the regulation heights (10, 11, and 12 cm) of the commercial blankets tested (LB1, SB1, SB2, and SB1-SB2). 
Table 1

ANOVA, for the case of commercial blankets, of the variables: size of IS 100; regulation height (gap) of the decelerator; type of blanket; on the maximum acceleration variable

\begin{tabular}{lcl}
\hline Variables & $F$ & $p$-level \\
\hline IS size & $3.43^{*}$ & 0.0330 \\
Gap & $3.03^{*}$ & 0.0487 \\
Type of blanket & $219.21^{*}$ & 0 \\
IS size-gap & 0.61 & 0.6553 \\
IS size-type of blanket & $16.93^{*}$ & $4.7035 \mathrm{E}-13$ \\
Gap-type of blanket & 1.11 & 0.3503 \\
IS size-gap-type of blanket & 1.70 & 0.0943 \\
\hline
\end{tabular}

(because of the high stiffness of the curtain). An ANOVA (Table 2) was applied to know the effect of height, number of curtains, and instrumented sphere sizes on the maximum acceleration value. All variables had a significant effect, being the height the most influential.

For a height of $-1.25 \mathrm{~cm}$, and six curtains, the average acceleration values registered by the instrumented spheres IS $100 \mathrm{P}, \mathrm{M}$, and $\mathrm{G}$, were respectively $25.5 \mathrm{~g}$, $22.8 \mathrm{~g}$, and $15.8 \mathrm{~g}$. The main inconvenience of this decelerator was that it tended to retain the fruit at the end of the ramp for a good setting (six curtains and $-1.25 \mathrm{~cm}$ height), when the decelerator was tested with flow of product on the line.

\subsection{Powered decelerator}

The intensity of the impacts registered by the IS 100 varied according to the size of IS (larger for the smallest
Table 2

ANOVA, for the case of multiple curtain, of the variables: size of IS 100; regulation height (gap) of the decelerator; number of curtains; on the maximum acceleration variable

\begin{tabular}{lcl}
\hline Variables & \multicolumn{1}{l}{$F$} & $p$-level \\
\hline IS size & $20.45^{*}$ & $4.0672 \mathrm{E}-09$ \\
Gap & $214.15^{*}$ & 0 \\
Number of curtains & $57.46^{*}$ & $3.2622 \mathrm{E}-13$ \\
IS size-gap & 0.89 & 0.4667 \\
IS size-number of curtains & 1.61 & 0.1998 \\
Gap-number of curtains & $15.42^{*}$ & $3.8498 \mathrm{E}-07$ \\
IS size-gap-number of curtains & 0.43 & 0.7847 \\
\hline
\end{tabular}

size), and height of the decelerator above the ramp (Fig. 8 , reduction in average $g$ values).

The effectiveness of the decelerator (reduction in the IS impact value without clogging the fruit) decreases when the height of decelerator above the ramp increases. This fact is more significant in the case of fruit of small diameter (IS 100P). When the elastic bands are touching the ramp $(0 \mathrm{~cm}$ height $)$, average acceleration values on impact on the receiving belt are always below $30 \mathrm{~g}$ (Fig. 8): $27.8 g$ for IS $100 \mathrm{P}, 22.8 \mathrm{~g}$ for IS $100 \mathrm{M}$, and $19.3 \mathrm{~g}$ for IS $100 \mathrm{G}$, and, in this case, the fruit keeps between each pair of elastic belts without passing across.

Using ANOVA it is shown (Table 3 ) that both variables had a significant effect (see $F$ value), the height being the most significant.

Fruit of a larger size is not as sensitive to variations in the height of the decelerator above the ramp, because it is impacting onto firm areas (more resistance to flexion)

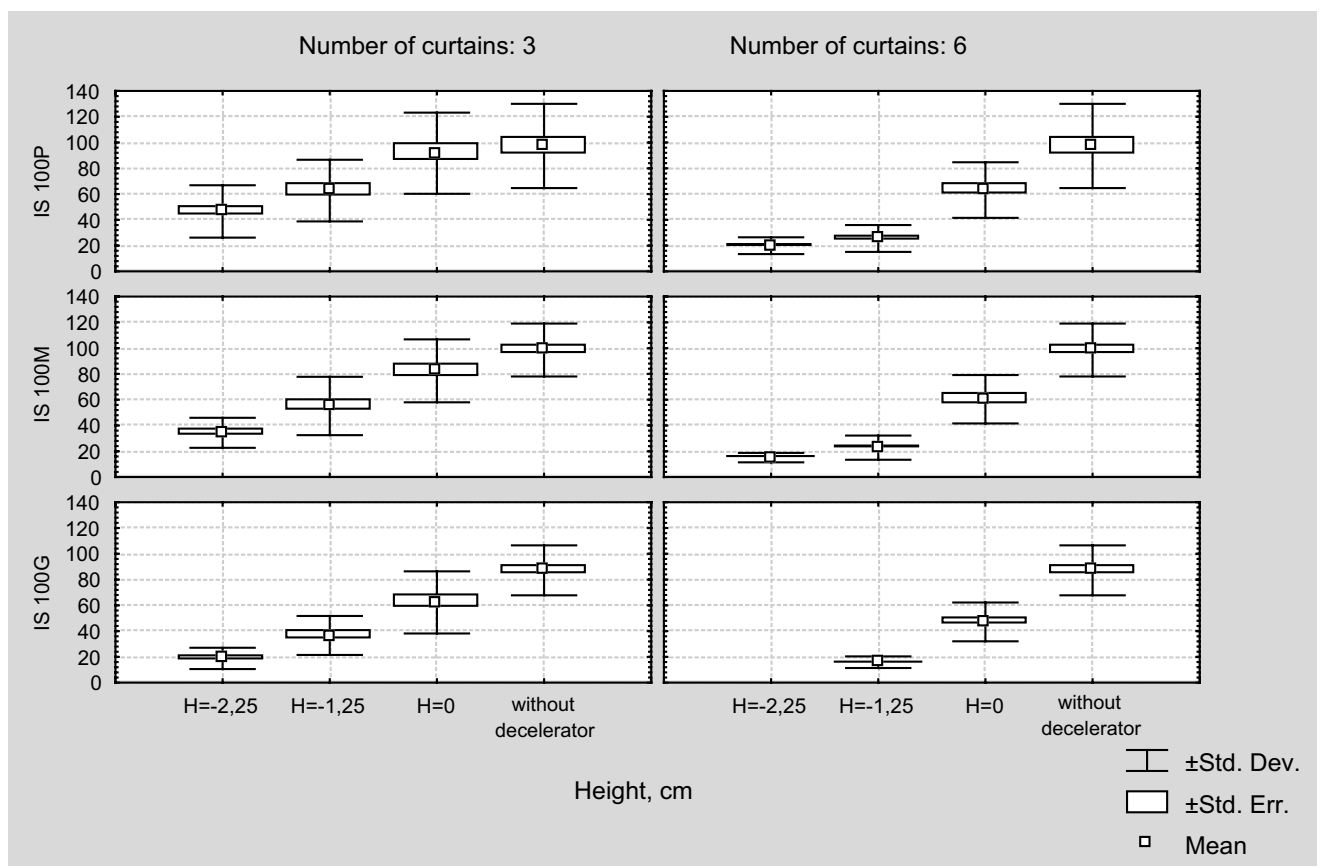

Fig. 7. Maximum acceleration registered by the instrumented spheres (IS $100 \mathrm{P}, \mathrm{M}$, and $\mathrm{G}$ ) in function of the regulation heights ( $-2.25,-1.25,0 \mathrm{~cm}$ ), and without decelerator of the multiple curtain. 


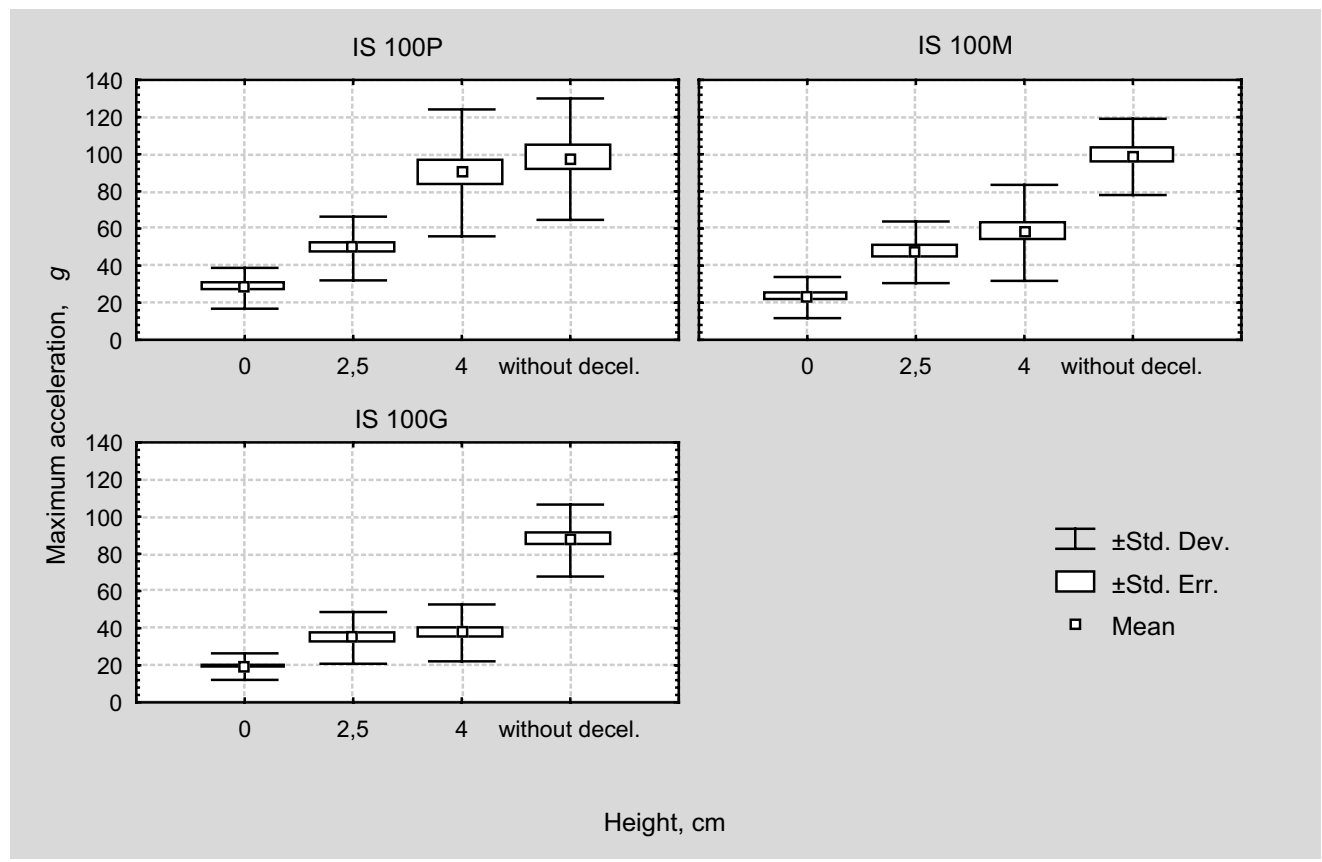

Fig. 8. Maximum acceleration registered by the instrumented spheres (IS 100P, M, and G) in function of the regulation heights of the curtains over the ramp $(0,2.5,4 \mathrm{~cm})$ on the powered decelerator and without decelerator.

Table 3

ANOVA, for the case of powered decelerator, of the variables: size of IS 100; regulation height (gap) of the decelerator; on the maximum acceleration variable

\begin{tabular}{lrl}
\hline Variables & \multicolumn{1}{l}{ F } & $p$-level \\
\hline IS size & $21.91^{*}$ & $1.9842 \mathrm{E}-09$ \\
Gap & $129.59^{*}$ & 0 \\
IS size-gap & $5.73^{*}$ & $1.4267 \mathrm{E}-05$ \\
\hline
\end{tabular}

of the elastic bands. On the other hand, small fruit pass across the elastic curtains easily at larger gaps, increasing the subsequent impact intensity.

\subsection{Considerations about the velocity at the end of the ramp}

An accurate estimation of the velocity of the instrumented spheres at the end of the ramp is rather difficult.
The IS 100 supplies, for each impact several values: maximum acceleration, duration (ms) and subsequently the velocity change. Then, if the velocity after the impact is unknown, and knowing the velocity change, we can estimate velocity ranges (minimum-maximum) for each situation.

Table 4 shows the velocity ranges for the IS $100 \mathrm{M}$ at the end of the ramp for different situations (each decelerator with its best setting and the ramp without decelerator) and the considerations about the flow of fruit for each case.

As it is shown, the powered decelerator set at $0 \mathrm{~cm}$ height supplies the lowest velocity at the end of the ramp (that of the decelerator, $20 \mathrm{~m} / \mathrm{min}=0.33 \mathrm{~m} / \mathrm{s}$, because the IS 100 keeps between each pair of curtains) without fruit flow retention. For the case of absence of decelerator, the velocity at the end of the ramp has been obtained using Eq. (7), without considering friction between IS 100 and ramp.

Table 4

Estimated velocities and flow of fruit for the IS $100 \mathrm{M}$ at the end of the ramp considering several situations: each decelerator with its best setting and ramp without decelerator

\begin{tabular}{lllll}
\hline Decelerators & Ramp without decelerator & $\begin{array}{l}\text { Blankets: SB2 at } 10 \mathrm{~cm}, \\
\text { and SB1 }+\mathrm{SB} 2 \text { at } 12 \mathrm{~cm} \\
\text { height }\end{array}$ & $\begin{array}{l}\text { Multiple curtain with six } \\
\text { curtains at }-1.25 \mathrm{~cm} \text { height }\end{array}$ & $\begin{array}{l}\text { Powered decelerator at } \\
0 \mathrm{~cm} \text { height }\end{array}$ \\
\hline $\begin{array}{l}\text { Velocity at the end of the } \\
\text { ramp (m/s) }\end{array}$ & 2.05 & $\cong 0.33$ & $\cong 0.33$ & 0.33 \\
\begin{tabular}{l} 
Flow of fruit \\
\hline
\end{tabular} & Bouncing problems & Flow retention $\rightarrow$ impacts & Flow retention $\rightarrow$ impacts & Fluent flow \\
\hline
\end{tabular}

Mantén aquí el mismo orden: 1-2-5-4-3. 


\section{Conclusions}

The powered decelerator, when correctly set (tips of the curtains touching the ramp), kept impact intensities below $30 \mathrm{~g}$, without retention of the product. Fruit kept between each pair of elastic curtains without passing across and was released with a low velocity to the band. For this setting, fruit size does not affect the performance of the decelerator.

Multiple curtains, when correctly set (six curtains, and height of $-1.25 \mathrm{~cm}$ with the curtain tip folded a length of $1.25 \mathrm{~cm}$ over the ramp) keep impact intensities below $30 \mathrm{~g}$. However, this setting of curtains may cause retention of fruit.

Commercial blankets also keep impact intensities below $40 \mathrm{~g}$, but cause some retention of product.

In conclusion, the analysed decelerators reduced the impact intensity to safe levels, with the powered decelerator being the most effective. The powered decelerator not only reduces impact, but also facilitates the flow of the product in the line.

\section{Acknowledgements}

Authors acknowledge the Spanish Commission of Science and Technology (CICYT, Project ALI 97-0954) and the Regional Community of Madrid (FPI scholarship) their support to this research project. The authors also acknowledge the support given by Prof. Emeritus Paul Chen for his igenious suggestions and his thorough revision of the manuscript.

\section{References}

Barreiro, P. (1994). Modelos para la simulación de daños mecánicos y desarrollo de un algoritmo de evaluación de maquinaria para los principales cultivares de albaricoque manzana melocotón y pera [Models to simulate mechanical damages and development of an evaluation algorithm for evaluating machinery for the most traded varieties of apricot, apple, peach and pear]. PhD thesis. UPM Madrid.

Bollen, A. F., \& De la Rue, B. T. (1990). Impact analysis using video with instrumented spheres. ASAE Paper No. 90-6078. ASAE Summer Meeting, Columbus, $\mathrm{OH}$.

Brown, G. K., Burton, C. L., Sargent, S. A., Schulte, N. L., Timm, E. J., \& Marshall, D. E. (1987). Apple packing line damage assessment. ASAE Paper No. 87-6515.

Chen, P., \& Sun, Z. (1981). Impact parameters related to bruise injury in apples. ASAE Paper 81-3041.

Guyer, D. E., Schulte, N. L., Timm, E. J., \& Brown, G. K. (1991). Minimizing apple bruising in the packing line. Cooperative Extension Service. Michigan State University. Extension Bulletin E-2290. March, 1991.

Miller, W. M., \& Wagner, C. J. (1991). Florida citrus packing line studies with an instrumented sphere. Applied Engineering in Agriculture, 7(5), 577-581.

Ortiz-Cañavate, J., García-Ramos, F. J., \& Ruiz-Altisent, M. (1999). Testing equipment for the improvement of mechanical devices to minimize damage to fruit in commercial packing lines. Symposium: Actual Tasks on Agricultural Engineering, Opatija, Croatia (pp. 223-229). ISBN: 953-6135-26-4.

Ortiz-Cañavate, J., García-Ramos, F. J., \& Ruiz-Altisent, M. (2000). Characterization of a right angle transfer point in a fruit packing line. Eur AgEng 2000, Warwick. Paper 00-PH-009.

Schulte, N. L., Timm, E. J., \& Brown, G. K. (1990). Apple, peach and pear impact damage thresholds. ASAE Paper No. 90-6002.

Zapp, H. R., Ehlert, S. H., Brown, G. K., Armstrong, P. R., \& Sober, S. S. (1989). Advanced Instrumentation Sphere (IS) for impact measurement. ASAE Paper No. 89-6046. 